Gut, 1978, 19, 371-376

\title{
Comparison of radio-opaque pellets and chromium sesquioxide as inert markers in studies requiring accurate faecal collections
}

\author{
W. J. BRANCH AND J. H. CUMMINGS \\ From the MRC Dunn Nutrition Unit, Cambridge and MRC Gastroenterology Unit, London
}

SUMMARY Radio-opaque pellets (ROP) similar to those currently used to measure gastrointestinal transit time have been compared with chromium sesquioxide to assess their suitability for use as inert markers in the gut. Five healthy subjects took both markers with every meal for two separate three week periods while taking metabolically controlled diets. Overall recovery of both markers was satisfactory; ROP $99.7 \pm 0.3 \%$ (SD) and chromium $97.8 \pm 1.6 \%$ (SD). A comparison of the amount of each marker recovered in 69 separate faecal collection periods of various lengths showed close agreement $(R=0.99)$ and the tail-off in marker excretion after cessation of $R O P$ and chromium intake was similar, although slightly more prolonged for chromium. The amount of marker retained in the gut was $13.5 \%$ greater for chromium at the end of the three week study periods. Both markers proved satisfactory for correcting variations in faecal calcium output. The ROP, however, offer clear advantages over chromium in that they are considerably easier and quicker to measure, the method of measurement using $x$-rays does not alter the stools and faecal handling is minimised. The precision of ROP measurement is greater and, because of the variety of ROP available, they offer more flexibility for metabolic studies. In addition, stool by stool analysis is possible enabling simultaneous measurement of mean transit time to be made in experimental subjects.

Inert markers have been used with increasing frequency over the past 30 years in human studies requiring accurate measurement of the output of faecal constituents. It has been shown that, by giving a marker to a subject regularly with the diet, normal variations in faecal output can be allowed for when calculating the output of faecal components, thus giving better reproducibility to balance data (Whitby and Lang, 1960; Rose, 1964). It is also possible, by use of inert markers to overcome the problems of inadequate faecal collections, to shorten balance periods, and to judge the existence of a steady state in dietary studies. More recently, it has been shown that continuously administered markers can be used to assess colonic function (Davignon et al., 1968; Cummings et al., 1976).

Several different types of marker have been tried including barium sulphate (Dick, 1967; Figueroa et al., 1968), copper thiocyanate (Dick, 1969), polyethylene glycol (Wilkinson, 1971), and chro-

Received for publication 2 December 1977 mium sesquioxide, which has become the best established and most widely preferred. Other markers, such as carmine and similar dyes, have been used in metabolic studies to indicate the start and finish of dietary periods but it is now felt that the use of single doses of marker alone for faecal studies is inaccurate (Rose, 1964; Sharpe and Robinson, 1970).

Whitby and Lang (1960) laid down criteria for the ideal intestinal marker which suggested that it should be inert, non-toxic, completely unabsorbed and non-metabolised, easily measured, have no appreciable bulk, and mix well with intestinal contents. No marker so far described has fulfilled these exacting criteria.

We report our experience using small radio-opaque pellets as markers in metabolic balance studies. In five healthy subjects we have compared during two separate three-week periods radio-opaque pellets (ROP) with chromium sesquioxide and find that the radio-opaque pellets offer distinct advantages. 


\section{Methods}

\section{PROTOCOL AND SUBJECTS}

Five healthy male medical students aged 22-24 years were studied, each for 10 consecutive weeks. The experimental design was as follows: weeks 1-3 markers taken, weeks 4, 5 no markers, weeks 6-8 markers taken, weeks 9,10 no markers. The subjects were on a metabolically controlled diet throughout the study except in the final week when they were allowed an ad libitum diet. The metabolic diet consisted of normal food of overall daily composition $2722 \mathrm{kcal}, 92 \mathrm{~g}$ protein, $111 \mathrm{~g}$ fat, $351 \mathrm{~g}$ carbohydrate, $17.6 \mathrm{~g}$ dietary fibre, and $1280 \mathrm{mg}$ calcium. Three one day menus of this composition were designed and fed in rotation. From weeks 4-9 $36 \mathrm{~g} / \mathrm{day}$ of pectin was added to the diet.

FAECAL COLLECTIONS

These were made throughout, each stool being collected separately into a plastic bag fixed over a toilet. The bag was then sealed, labelled, and stored at $-20^{\circ} \mathrm{C}$. Each stool was individually analysed for radio-opaque markers but for measurement of chromium the stools were pooled as shown in Table 1 . There were $4 \times 14$ day collection periods, $15 \times 7$ day collections, $27 \times 4$ day collections, and $27 \times 3$ day collections - a total of 73 collection periods.

Table 1 Pooling of faecal samples for chromium analysis

\begin{tabular}{lll}
\hline Week & Collection no. & No. of days in collection \\
\hline 1 & 1 & 7 \\
2 & 2 & 3 \\
3 & 3 & 4 \\
& 4 & 3 \\
4 & 5 & 4 \\
& $6^{*}$ & 4 \\
5 & 7 & 3 \\
& 8 & 3 \\
6 & 9 & 4 \\
7 & 10 & 7 \\
& 11 & 3 \\
8 & 12 & 4 \\
9 & 13 & 7 \\
& $14^{*}$ & 3 \\
10 & 15 & 4 \\
& 16 & 3 \\
\hline
\end{tabular}

*For subjects $\mathrm{Y}$ and We periods 6-9 and 14-17 were combined.

\section{MARKERS}

The radio-opaque markers were $3 \mathrm{~mm}$ sections cut from Portex radio-opaque tubing $R_{1}$ external diameter $1.5 \mathrm{~mm}$. After cutting they were extracted overnight with toluene in a large Soxhlet apparatus to remove the plasticiser. The resulting pellets weighed $4.4 \mathrm{mg}$ and had a specific gravity of $2 \cdot 1$.
Gelatin capsules were then filled each with 10 markers.

The chromium sesquioxide was obtained in capsules from Sandoz Products, Feltham, Middlesex, each capsule containing $250 \mathrm{mg} \mathrm{Cr}_{2} \mathrm{O}_{3}$.

The subjects were fed one capsule of each marker with each meal (three per day) for 21 days-a total daily dose of 30 radio-opaque pellets and $750 \mathrm{mg} \mathrm{Cr}_{2} \mathrm{O}_{3}$.

\section{ANALYSIS}

The radio-opaque markers were analysed by radiographing each individual stool. Details of this procedure have been described previously (Cummings et al., 1976).

The stools were then pooled into the designated collection periods, distilled water added and homogenised using a Silverson homogeniser for 10 minutes. Duplicate aliquots of homogenate were taken while the homogeniser was still running and were freeze dried; $0.5-1.0 \mathrm{~g}$ aliquots of the freeze dried material was analysed for chromium using a modification of the method of Bolin et al. (1952). Duplicate aliquots of freeze dried stool were weighed accurately into $50 \mathrm{ml} \mathrm{Kjeldahl} \mathrm{flasks.} \mathrm{Ten} \mathrm{millilitres}$ of oxidising reagent were then added taking care to wash down any sample into the flask (two to three small glass beads were added to prevent bumping). The sample was heated until the digest cleared and the green sesquioxide was converted to orange dichromate. The flask was allowed to cool and $4 \mathrm{ml}$ perchloric acid (specific gravity 1.74 ) added washing down the vessel walls. Heating was continued for two to three minutes and the flask allowed to cool. Adequate safety precautions had to be taken during the perchloric acid digestion. The digest was transferred quantitatively to a $100 \mathrm{ml}$ volumetric flask and made up to the mark. A sample of this was transferred to a centrifuge tube and centrifuged at $3000 \mathrm{rpm}$ for five to 10 minutes to remove any precipitate. The absorbance of the extract was measured at $435 \mathrm{nM}$ against a reagent blank and compared with a dichromate standard.

Faecal calcium was also measured in duplicate aliquots of freeze dried faecal homogenate. The aliquots were dry ashed at $400^{\circ} \mathrm{C}$ and the ash dissolved in nitric acid. Calcium was measured by atomic absorption spectroscopy after dilution with Lanthanum: $\mathrm{HCl}$ solution.

All data given in the paper are at \pm 1 standard deviation.

\section{Results}

All the subjects had a normal bowel habit throughout the study, their mean daily faecal weight being 
$135 \pm 67 \mathrm{~g} /$ day, average number of bowel actions per week $4.6 \pm 1.5$ and mean transit time (measured by the continuous marker method of Cummings et al., 1976) $71 \pm 30 \mathrm{~h}$. No unwanted effects from either marker was noticed by the subjects and there was no detectable change in gastrointestinal function attributable to the markers.

MARKER RECOVERIES AND METHODOLOGY

The described perchloric acid oxidation method for measuring chromium sesquioxide proved satisfactory provided due care was given to adequate faecal homogenisation and careful safety precautions were followed. The overall coefficient of variation on duplicate samples of homogenate was $6.6 \%$. Part of this variation was because precision of the method was relatively poor at low concentrations of chromium. When there was less than $1 \mathrm{mg}$ chromium per gram of freeze dried stool the coefficient of variation was $15.1 \%$. Measurement of the radio-opaque pellets suffered from no such lack of precision, it being equally simple to count either small or large numbers in a whole stool. Twohundred-and-thirty-one stools were radiographed twice and the markers counted. On 30 occasions the counts were not identical, giving an overall coefficient of variation of $1 \cdot 1 \%$.

The $\mathrm{Cr}_{2} \mathrm{O}_{3}$ capsules were said by the manufacturers to contain $170.8 \mathrm{mg}$ chromium. Eight were taken at random and the chromium measured. The mean value was $170 \pm 7 \mathrm{mg}$.

Table 2 shows the marker recoveries from each of the 10 study periods. For both markers overall recovery was very good; chromium $97.8 \pm 1.6 \%$ and ROP $99.7 \pm 0.3 \%$. Of the 6310 ROP taken by the subjects, 19 were not recovered.
Table 2 Marker recoveries*

\begin{tabular}{|c|c|c|c|c|c|}
\hline \multirow[t]{2}{*}{ Subject } & \multirow[t]{2}{*}{ Weeks } & \multicolumn{2}{|c|}{$\begin{array}{l}\text { Radio-opaque pellets } \\
\text { recovered }\end{array}$} & \multicolumn{2}{|c|}{ Chromium recovered } \\
\hline & & (No.) & $(\%)$ & $(m g)$ & $(\%)$ \\
\hline \multirow[t]{2}{*}{$\mathbf{Y}$} & $1-5$ & 628 & $99 \cdot 7$ & 10438 & $97 \cdot 4$ \\
\hline & $6-10$ & 627 & $99 \cdot 5$ & 10288 & 96.0 \\
\hline \multirow[t]{2}{*}{ We } & $1-5$ & 628 & $99 \cdot 7$ & 10574 & $98 \cdot 7$ \\
\hline & $6-10$ & 626 & $99 \cdot 4$ & 10358 & 96.6 \\
\hline \multirow[t]{2}{*}{ D } & $1-5$ & 627 & $99 \cdot 5$ & 10853 & $101 \cdot 3$ \\
\hline & $6-10$ & 631 & $100 \cdot 2$ & 10631 & $99 \cdot 2$ \\
\hline \multirow[t]{2}{*}{ Wo } & $1-5 \dagger$ & 637 & 99.5 & 10613 & $97 \cdot 5$ \\
\hline & $6-10$ & 629 & $99 \cdot 8$ & 10414 & $97 \cdot 2$ \\
\hline \multirow[t]{2}{*}{$\mathbf{K}$} & $1-5$ & 629 & 99.8 & 10491 & 97.9 \\
\hline & $\begin{array}{l}6-10 \\
\text { Mean \% } \\
\text { recovery }\end{array}$ & $\begin{array}{l}630 \\
99 \cdot 7 \pm 0 \cdot 3\end{array}$ & 100 & $\begin{array}{l}10348 \\
97 \cdot 8 \pm 1 \cdot 6\end{array}$ & $96 \cdot 6$ \\
\hline
\end{tabular}

*Amount of markers given in each three week period was: radioopaque pellets 630 ; chromium $10,713 \mathrm{mg}$.

†Subject took an extra dose of each marker during this period.

\section{COMPARISON OF MARKERS}

When the amount of the two markers recovered in each collection period was compared there was a good overall correlation (Fig. 1). In four of the 73 collection periods neither marker was present in the stool leaving 69 periods in which to compare the recoveries. The correlation was $r=0.99, \mathrm{P}<0.001$.

The tail-off of the two markers during the final two weeks of each study period was compared in detail in three subjects (Wo, D, K) by dividing each week into a three and four day collection period. Chromium was detected in all but three of the collections, while ROPs were absent from 11, suggesting a longer tail in the excretion of chromium. However, as may be seen in Fig. 2, the actual amounts present after the first week were extremely small,

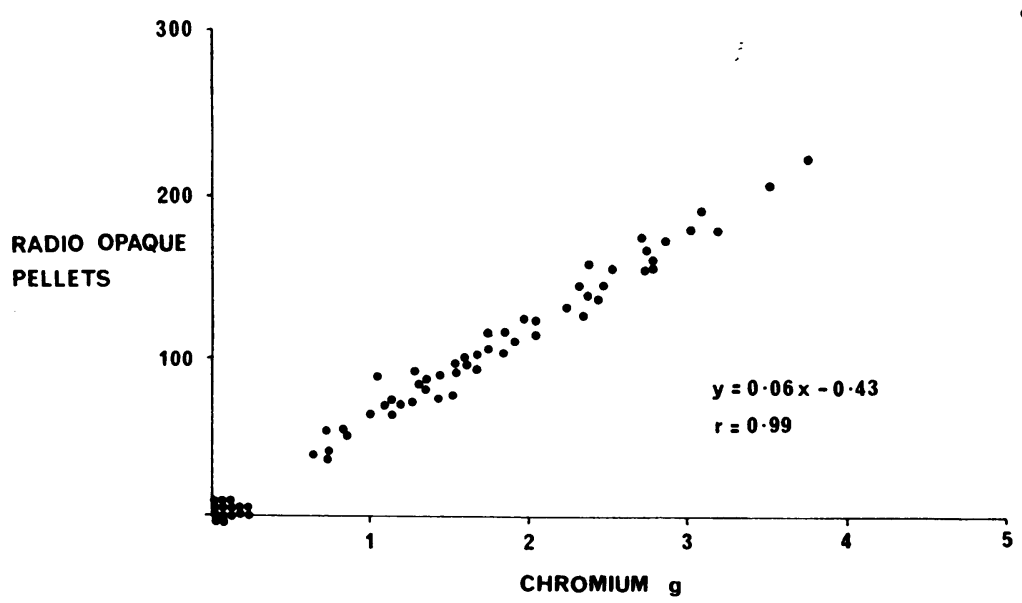

Fig. 1 A comparison of the amounts of chromium and radio-opaque pellets excrete in each collection period $(N=69)$. 

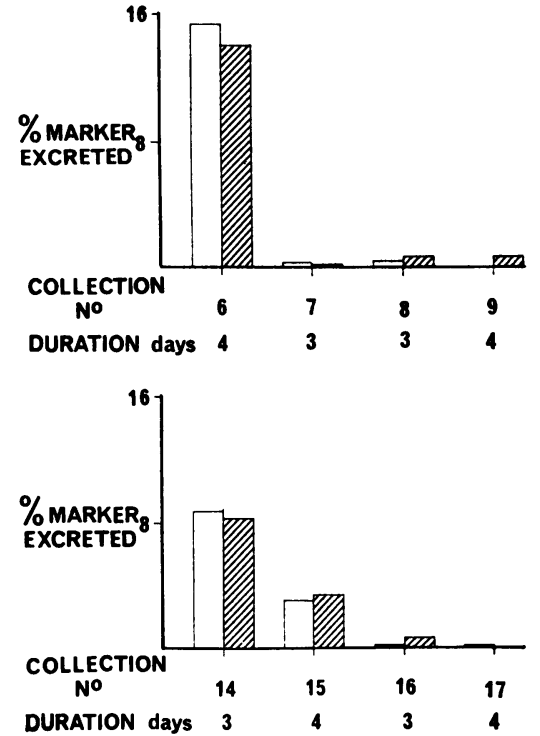

Fig. 2 Combined total of marker excreted ( $\%$ ) for three subjects $(D, K$, and $W o)$ during the two two-week periods after marker intake had been discontinued. Top: first two-week period; Bottom: second two-week period. $\square=$ radio-opaque pellets. Collection numbers as in Table 1.

totalling no more than $1-2 \%$ of the ingested dose, and when taken with the appearance of an occasional ROP during this time left very little real difference in the final excretion of the markers.

A more sensitive way of looking at differences in the way markers behave is to calculate the amount of marker retained in the gut (amount ingested amount excreted) at a given time. This has been calculated for each marker at midnight on the last day of each of the three weeks during which the markers were fed. Figure 3 shows the amount of marker retained, expressed as days of intake (amount marker retained $\div$ amount fed daily), at the end of each week of the 10 three week study periods. The average amount of ROP and chromium retained respectively at the end of the first week of marker intake is $3.09 \pm 1.45$ days and $3.00 \pm 1.47$ days; at the end of the second week of marker intake $3.25 \pm 1.83$ and $3.45 \pm 1.67$; and at the end of the third week of marker intake $2.81 \pm 1.44$ and $3 \cdot 19 \pm 1 \cdot 41$. The difference between the amounts retained at the end of the third week is significant, $t=3.10, \quad \mathrm{P}<0.025$. The amount of chromium retained was $13.5 \%$ more than the pellets and suggests that if these two markers were used to measure mean transit time through the gut the value for $\mathrm{Cr}_{2} \mathrm{O}_{3}$ will be accordingly longer.

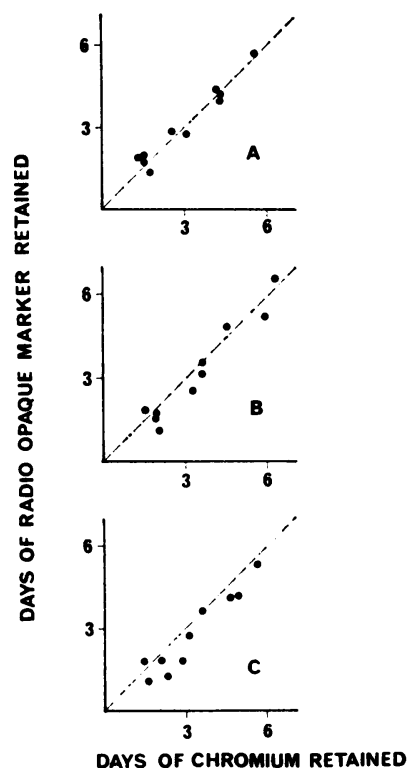

Fig. 3 The amount of both markers retained in the gut at the end of each of the two three-week marker intake periods. A: pooled data from first week of each period; $B$ : second weeks; $C$ : third weeks. Dotted line that of perfect agreement.

\section{USE OF MARKERS TO CORRECT BALANCE}

DATA

One of the primary uses of inert markers is to correct for variability in output of faecal constituents. Such corrections are essential in studies of calcium metabolism because small changes in calcium balance are sought. We have therefore used the data from both $\mathrm{Cr}_{2} \mathrm{O}_{3}$ and $\mathrm{ROP}$ to correct faecal calcium outputs and in Fig. 4 the results are shown for representative periods in three subjects. Both markers clearly reduce the variability in faecal calcium output seen in the three and four day collection periods during the final two weeks of the first marker study in each subject.

These data emphasise the need for markers when doing such studies. During the second and third weeks of each study period, when the subjects should have been in a steady state, considerable variability in faecal output was seen. In the study as a whole the three-day collections $(n=14)$ contained between $2 \cdot 1-5 \cdot 7$ days intake of marker, the four-day collections $(n=15)$ from $2 \cdot 4-6 \cdot 0$ days intake of marker, and the seven-day collections $(n=10)$ from $6 \cdot 0-10 \cdot 4$ days intake of marker.

\section{Discussion}

Both markers proved satisfactory in this study with 
good overall recoveries, acceptable precision in their measurement and complete inertness in the gut so far as can be judged. The radio-opaque pellets, however, offer numerous practical advantages over chromium sesquioxide.

The pellets were considerably easier to measure. The technique of radiographing faecal specimens is very simple and overcomes the need for complete homogenisation of samples with its attendant possible errors in mixing and aliquoting. Handling of the specimens is reduced to a minimum by radiography and the danger of explosion with the perchloric acid digestion of $\mathrm{Cr}_{2} \mathrm{O}_{3}$ is avoided. In addition, marker determination by radiography does not destroy the specimens.

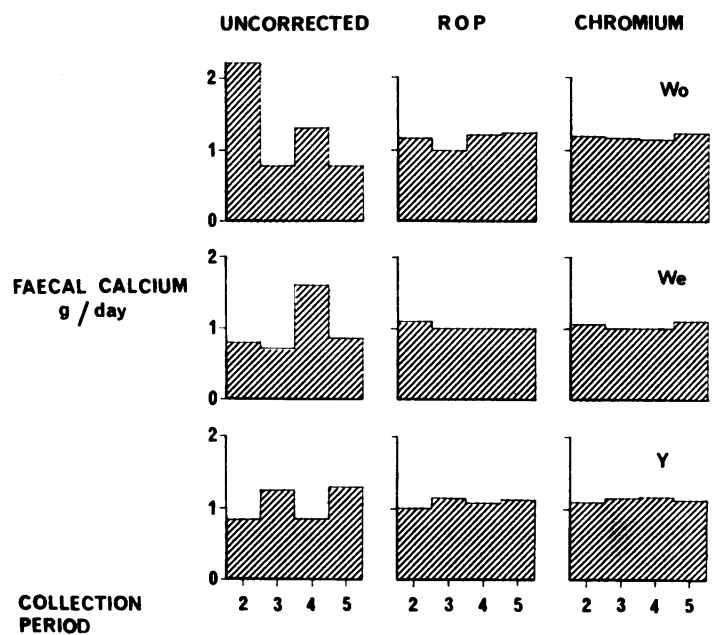

Fig. 4 Faecal calcium excretion (g/day) during four consecutive collection periods (weeks 2 and 3) in three subjects.

It is not always easy to assess the time spent on a particular technique in a busy laboratory, particularly when other jobs can be interspersed with the one in hand. By any standard, however, the radioopaque pellet method was considerably quicker. We were able to process completely $12-15$ stools per hour, whereas chromium determinations, after the homogenising and freeze drying stage which is common to many analytical procedures, were done at a rate of about 12 samples per day. This relative ease of measurement allows a stool by stool analysis to be done with the result that a mean transit time for the marker can be calculated throughout the study (Cummings et al., 1976).

Measurement of $\mathrm{Cr}_{2} \mathrm{O}_{3}$ has always proved difficult, largely because of the problems of solubilising a highly insoluble substance. It is not surprising, therefore, to find quite a large coefficient of variation
$(6.6 \%)$ when measuring it. This value is higher than some other workers have reported (Whitby and Lang, 1960; Davignon et al., 1968; Lentner et al., 1975) but was largely accounted for by inaccuracies in measuring chromium at low levels. The radio-opaque pellets suffered no such disadvantage.

A further advantage of the pellets is that several different types can be made. This enables different pellets to be given in different weeks or in separate parts of a dietary study and so enable faecal material from each part of the study to be clearly identified, while maintaining a continuous flow of marker. Mean transit time can also be calculated from the pellets, making it easier to predict when a steady state has been reached and the faeces have reached equilibrium on a new diet.

Apart from the practical differences in measurement of the two markers, they compared very closely with each other. The correlation shown in Fig. 1 between the output of each marker in each collection period and the similar result produced when both were used to correct faecal calcium outputs (Fig. 4) suggest that they are behaving almost identically in the gut. When the amount of each marker retained in the gut was calculated (Fig. 3) a small difference did emerge. The amount of chromium retained was $13.5 \%$ more than the pellets at the end of the third week of each study period. This result is not altogether surprising as the two markers differ considerably in particle size and specific gravity. One of the factors known to affect the passage of markers through the gut is specific gravity (Hoelzel, 1930; Kirwan and Smith, 1974). In general, substances with a high specific gravity (SG) travel slower than those of lower specific gravity. The $\mathrm{SG}$ of $\mathrm{Cr}_{2} \mathrm{O}_{3}$ is 5.2 and the radio-opaque pellets $2 \cdot 1$ which suggest that the $\mathrm{Cr}_{2} \mathrm{O}_{3}$ should travel more slowly and give a larger pool size, as was seen in this study. It is clear also that, when different markers are used to measure pool size and mean transit time in the gut, the answer obtained will depend on the characteristics of the marker being used.

During analysis of the specimens it was apparent that chromium could be detected for some while after all the pellets had been excreted. When this observation was put to the test (Fig. 2) no real difference in the tail-off of marker existed. The apparently long tail of chromium was due to the presence of very small amounts in the collection periods. The slightly longer retention time of $\mathrm{Cr}_{2} \mathrm{O}_{3}$ would be expected to produce a longer tail-off period. A stool by stool analysis for chromium would probably be required to show this effectively.

This study again confirms the need for markers in 
investigations requiring accurate measurement of faecal output. Faecal output varies considerably and rarely does a day's stool represent the residue from a day's diet. Even in seven day collections during this study marker output suggested that there was from 6.0 to 10.4 days of dietary residue present. The range of values for the four day collections was greater at 2.4-6.0 days intake of marker. When it is remembered that hospital inpatient faecal collections are often for four days in poorly motivated subjects some idea of the likely accuracy of such collections can be made.

The value of markers is further confirmed in Fig. 4 where faecal calcium output data are corrected for marker output. When added to the subjects' urine output data, satisfactory overall balances were achieved.

In conclusion, we suggest that, where an inert marker is needed in balance or other gastrointestinal studies, then radio-opaque pellets are a suitable choice. They behave very similarly to the widely used $\mathrm{Cr}_{2} \mathrm{O}_{3}$ in the gut but offer clear advantages in terms of ease of measurement, safety in the laboratory, speed, and accuracy. They enable simultaneous measurements of mean transit time to be made and, by the use of different shaped pellets, flexible dosage schedules can be drawn up to demarcate dietary and other study periods.

This study has been done in normal subjects but there is no reason to believe that the pellets would not be suitable for use in patients with gastrointestinal disturbances. It would greatly enhance the value of a faecal fat collection if by a single radiograph its marker content could be measured. While these markers may behave differently in subjects with more watery stools, provided they are in a steady state with regard to both marker excretion and the substance being studied, such corrections should be valid.

Our thanks are due to Dr Hugh Wiggins for help in making the pellets and for many discussions about the use of markers. We are also grateful to the medical students who did the studies so carefully and reliably.

\section{References}

Bolin, D. W., King, R. P., and Klosterman, E. W. (1952). A simplified method for the determination of chromic oxide $\left(\mathrm{Cr}_{2} \mathrm{O}_{3}\right)$ when used as an index substance. Science, 116, 634-635.

Cummings, J. H., Jenkins, D. J. A., and Wiggins, H. S. (1976). Measurement of the mean transit time of dietary residue through the human gut. Gut, 17, 210-218.

Davignon, J., Simmonds, W. J., and Ahrens, E. H., Jr. (1968). Usefulness of chromic oxide as an internal standard for balance studies in formula-fed patients and for assessment of colonic function. Journal of Clinical Investigation, 47, 127-138.

Dick, M. (1967). Use of barium sulphate as a continuous marker for faeces. Journal of Clinical Pathology, 20, 216-218.

Dick, M. (1969). Use of cuprous thiocyanate as a short-term continuous marker for faeces. Gut, 10, 408-412.

Figueroa, W. G., Jordan, T., and Bassett, S. H. (1968). Use of barium sulfate as an unabsorbable fecal marker. American Journal of Clinical Nutrition, 21, 1239-1245.

Hoelzel, F. (1930). The rate of passage of inert materials through the digestive tract. American Journal of Physiology, 92, 466-497.

Kirwan, W. O., and Smith, A. N. (1974). Gastrointestinal transit estimated by an isotope capsule. Scandinavian Journal of Gastroenterology, 9, 763-766.

Rose, G. A. (1964). Experiences with the use of interrupted carmine red and continuous chromium sesquioxide marking of human faeces with reference to calcium, phosphorus, and magnesium. Gut, 5, 274-279.

Sharpe, S. J., and Robinson, M. F. (1970). Intermittent and continuous faecal markers in short-term metabolic balance studies in young women. British Journal of Nutrition, 24, 489-500.

Whitby, L. G., and Lang, D. (1960). Experience with the chromic oxide method of fecal marking in metabolic balance investigations on humans. Journal of Clinical Investigation, 39, 854-863.

Wilkinson, R. (1971). Polyethylene glycol 4000 as a continuously administered non-absorbable faecal marker for metabolic balance studies in human subjects. Gut, 12, 654-660. 